\title{
Ten fundamental questions for water resources development in the Ganges: myths and realities
}

\author{
Claudia Sadoffa,*, Nagaraja Rao Harshadeep ${ }^{a}$, Donald Blackmore ${ }^{\mathrm{b}}$, \\ Xun $\mathrm{Wu}^{\mathrm{c}}$, Anna O’Donnella, Marc Jeuland ${ }^{\mathrm{d}}$, Sylvia Lee \\ and Dale Whittington ${ }^{\mathrm{f}}$ \\ ${ }^{a}$ The World Bank, Washington, USA \\ *Corresponding author. E-mail: csadoff@worldbank.org \\ ${ }^{b}$ Independent consultant, Canberra, Australia \\ ${ }^{c}$ National University of Singapore, Singapore \\ ${ }^{d}$ Duke University, Durham, USA \\ ${ }^{e}$ Skoll Global Threats Fund, San Francisco, USA \\ ${ }^{f}$ University of North Carolina at Chapel Hill and Manchester Business School, Manchester, UK
}

\begin{abstract}
This paper summarizes the results of the Ganges Strategic Basin Assessment (SBA), a 3-year, multi-disciplinary effort undertaken by a World Bank team in cooperation with several leading regional research institutions in South Asia. It begins to fill a crucial knowledge gap, providing an initial integrated systems perspective on the major water resources planning issues facing the Ganges basin today, including some of the most important infrastructure options that have been proposed for future development. The SBA developed a set of hydrological and economic models for the Ganges system, using modern data sources and modelling techniques to assess the impact of existing and potential new hydraulic structures on flooding, hydropower, low flows, water quality and irrigation supplies at the basin scale. It also involved repeated exchanges with policy makers and opinion makers in the basin, during which perceptions of the basin could be discussed and examined. The study's findings highlight the scale and complexity of the Ganges basin. In particular, they refute the broadly held view that upstream water storage, such as reservoirs in Nepal, can fully control basinwide flooding. In addition, the findings suggest that such dams could potentially double low flows in the dry months. The value of doing so, however, is surprisingly unclear and similar storage volumes could likely be attained through better groundwater management. Hydropower development and trade are confirmed to hold real promise (subject to rigorous project level assessment with particular attention to sediment and seismic risks) and, in the near to medium term, create few significant tradeoffs among competing water uses. Significant uncertainties - including climate change - persist, and better data would allow the models and their results to be further refined.
\end{abstract}

Keywords: Ganges; Hydro-economic modelling; International rivers; River basin management; South Asia water; Transboundary waters

doi: 10.2166/wp.2013.006

C IWA Publishing 2013 


\section{Introduction}

The Ganges is the most populous river basin in the world (Figure 1). It presents both great opportunities and great challenges. The daily lives of 655 million inhabitants depend on the water that the Ganges and its tributaries provide for drinking, agriculture, hydropower generation, and for navigational and ecosystem services. All countries in the basin benefit from the Ganges and suffer from its extremes; all could benefit more and suffer less from the devastating floods and periodic droughts which routinely undermine development in the region. There are many opportunities for cooperation and productive management of the river (Swain, 1993; Huda \& Shamsul, 2001; Rahaman, 2009).

Currently, however, most development in the basin is through incremental, project-by-project activities within each of the riparian countries, in part due to gaps in information and knowledge about the basin. Information and data are surprisingly scarce and difficult to obtain. There has been surprisingly little systematic regional research on the basin's development options and challenges using modern analytical tools that go beyond sector, country or state analysis to examine the larger strategic questions that the basin faces (Ahmad, 2003). As a result, perceptions of current conditions and future development paths in the Ganges basin vary dramatically within and among different stakeholder groups, institutions and countries.

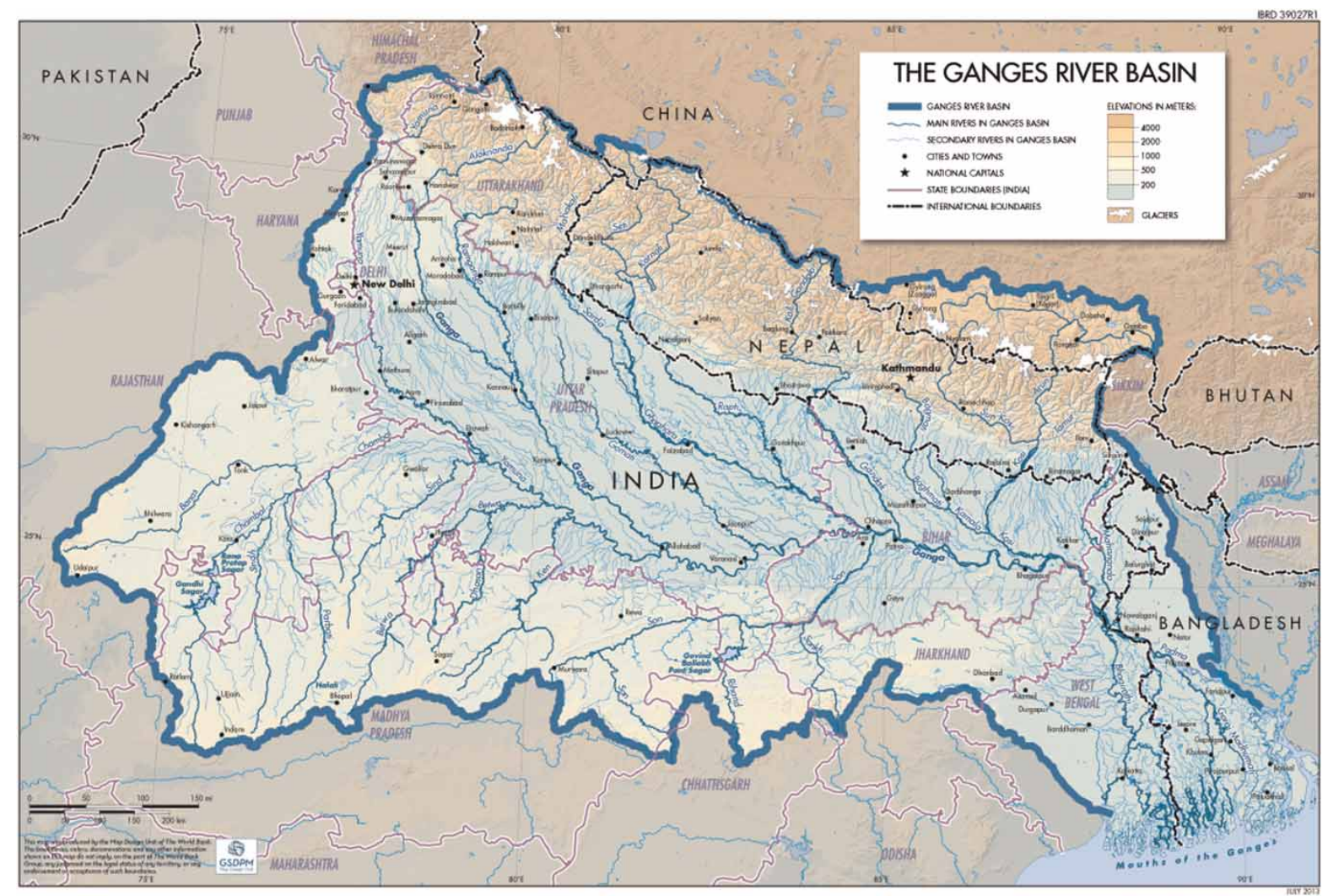

Fig. 1. The Ganges River basin. (Full colour versions of all the figures in this paper appear online.) 
The Ganges Strategic Basin Assessment (SBA), a 3-year, multi-disciplinary effort undertaken by a World Bank team in cooperation with several leading regional research institutions, involved repeated exchanges with policy makers and opinion makers in the basin, and was aimed at filling a crucial knowledge gap. Advances in remote sensing, hydrological modelling and forecasting capabilities, and open access data platforms now make an unprecedented wealth of information available to all. These advances offer the basin countries an opportunity to 'leap frog' the technologies and methods they use to gather, manage, analyse and share information. The Ganges SBA identified ways in which information can be generated and used to strengthen planning and decision making in the Ganges basin, and seek evidence-based opportunities for mutually beneficial cooperation. Significant efforts were made to assemble the data sets used in this analysis, drawing on publicly available data in Bangladesh, India and Nepal, and on global data sets.

A set of hydrological and economic models for the Ganges system was developed and tested under the Ganges SBA. These models are believed to be adequate for assessing the impact of existing and new hydraulic structures on flooding, hydropower, low flows, water quality and irrigation supplies at the basin scale. The Ganges SBA focuses only on basin-level dynamics; any specific projects under consideration would still require full economic, environmental and social assessments with specific attention to local ecological, seismic and cultural contexts. Significant uncertainties - including climate change - persist and better data would allow the models to be further refined. We believe the basic conclusions based on the model results are robust and we have used them to develop strategic insights.

The results of the Ganges SBA - summarized in this paper - challenge some long-held beliefs about the Ganges River basin, suggesting that some of what has long been considered 'common knowledge' is, in fact, inaccurate. The Ganges SBA highlights the complexity of the Ganges basin and demonstrates an urgent need for a shared understanding of the full basin system. The system is so large and complex that it simply cannot be fully understood intuitively. Commonly held perceptions are re-examined using modern data sources and modelling techniques to come to fact-based understandings about the basin's resources and possible future development paths.

The paper is structured to answer 10 fundamental questions based on the new information obtained from our modelling and analysis in the Ganges SBA:

1. Is there substantial potential for upstream reservoir storage in the Himalayan headwaters of the basin?

2. Can upstream water storage control basin-wide flooding?

3. Can upstream water storage augment low flows downstream?

4. Are there good alternatives or complements to reservoir storage?

5. Is there substantial untapped hydropower potential in the Ganges basin?

6. What is the magnitude of potential economic benefits from multi-purpose water infrastructure and what are the tradeoffs between different water uses?

7. What are the cost- and benefit-sharing dynamics of upstream water storage development?

8. Is infrastructure the best strategy for protecting communities from floods?

9. Is it possible to control sediment in the Ganges?

10. How will climate change affect the Basin?

The above list is not an exhaustive set of questions about the behaviour of and development options for the Ganges basin. Instead, this list was created to stimulate discussion of some of the most critical issues that the riparian countries will need to grapple with as they manage and develop their shared water 
resources. The findings demonstrate an urgent need for a shared evidence-based understanding of the full basin system, calling for significantly enhanced regional cooperation in water, weather and climate information, along with operational modelling, and forecast and warning systems. These are critical initial steps towards the sustainable management of the basin, and the safety and prosperity of its people.

\section{Question 1. Is there substantial potential for upstream reservoir storage in the Himalayan headwaters of the basin?}

Much has been written about the potential for large water storage structures in the Nepal Himalaya (Khan, 1996; Mirza, 1998; Ahmad \& Ahmed, 2005; Rahaman, 2005). It is generally assumed that this potential could be harnessed through large multi-purpose dams to produce hydropower, deliver more timely irrigation water and regulate the extreme flows of the Ganges River.

The SBA found that the potential reservoir storage volume in the Nepal Himalaya is low relative to the flow of the river. Although many reservoir sites in the Himalaya are attractive for the development of multi-purpose water storage infrastructure, the steep terrain and mountain gorges mean that surprisingly little water can be stored behind even very high dams. Developing all 23 of the proposed large-scale structures that we examined in Nepal (including the Kosi, Chisapani and Pancheswar dams) would provide additional active storage equivalent to about $18 \%$ of the basin's annual average flow. The aggregate active storage on the river system (including storage in Bangladesh, India and Nepal) would reach 130-145 billion ${ }^{1}$ cubic meters (bcm). This amount of storage is quite small compared with the 500 billion $\mathrm{m}^{3}$ average annual flow of the Ganges River and the 1,200 billion $\mathrm{m}^{3}$ average annual rainfall within the basin. This additional storage would allow for some redistribution of flows within a year, but it would not allow for any significant storage across years (see Figure 2). As a point of comparison, man-made storage capacity on many major rivers such as the Colorado, Murray-Darling and Nile Rivers, is 100-200\% of the mean annual flow which allows for multi-year storage operations.

The dams would also be very costly; the 23 large infrastructures proposed would require capital investment of roughly US\$35 billion (in 2010 dollars) and would likely take decades to construct.

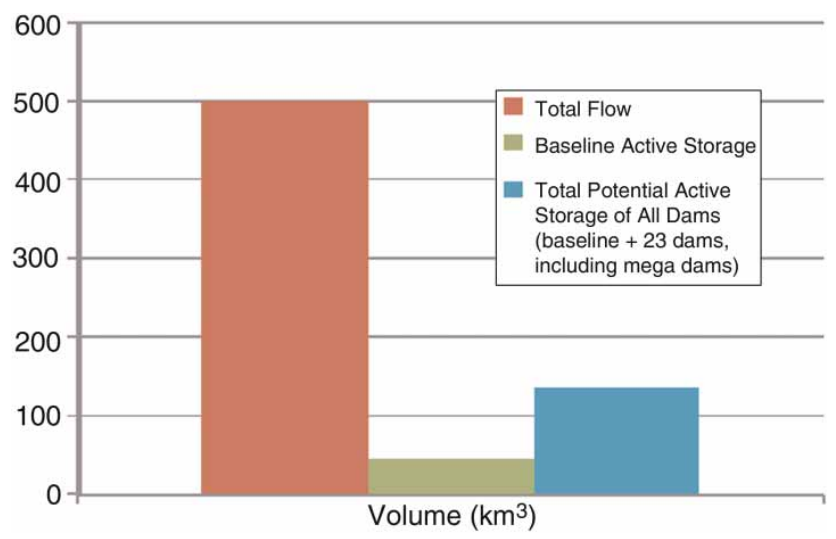

Fig. 2. Current and potential surface water storage in the Ganges basin.

\footnotetext{
${ }^{1} 1$ billion $=1 \times 10^{9}$ throughout.
} 
Moreover, the extent to which dams in Nepal can be operated while efficiently passing the large amounts of sediment eroded from high in the Himalaya remains unclear.

While man-made storage potential in the Ganges is lower than generally believed, the natural groundwater storage potential is apparently far greater. The Ganges is endowed with one of the world's largest groundwater aquifers that could provide immense natural water storage, assuming energy were available to pump the groundwater. While the use of groundwater storage is unlikely to provide significant flood control benefits at the basin scale, it could provide significant water security for irrigation in some parts of the basin.

\section{Question 2. Can upstream water storage in Nepal control flooding downstream?}

Large Himalayan dams in Nepal are commonly seen as the answer to the flooding that plagues the Ganges plains and delta, especially in areas of eastern Uttar Pradesh, Bihar and Bangladesh (Huda \& Shamsul, 2001; Onta, 2001; Salman \& Uprety, 2002). Model results and research reveal a different picture.

The potential to control floods using upstream storage in Nepal is very limited. The active storage potential examined in the SBA (existing storage plus additional major storage in the Nepal Himalaya) amounts to approximately $25-30 \%$ of average annual river flows. This is simply too small a percentage to meaningfully regulate the full river system, even if dams were operated for the sole purpose of providing flood control. This limited potential storage severely constrains riparians' ability to ever truly regulate this river system, even assuming an aggressive development of system surface storage.

On the other hand, the lack of substantial regulation will preserve a more natural hydrology in the river system (if irrigation diversions are stabilized), which provides a wide variety of ecosystem services that have not been quantified.

The Kosi River is a major, flood-prone tributary of the Ganges. The Ganges SBA models indicate that even the very large proposed Kosi High Dam could not fully control flood peaks in that river. The Kosi High Dam would provide 9.5 billion $\mathrm{m}^{3}$ of live storage. But it would be built on a river with an average annual flow of 55 billion $\mathrm{m}^{3}$ (much higher in peak flood years) and could therefore regulate only a small part of the floodwaters during the monsoon season.

Moreover, the important question is not whether the Kosi High Dam could reduce flood peaks but whether reducing flood peaks in the Kosi River would stop flooding in southeastern Nepal and Bihar. Unfortunately, the evidence suggests that the dam's impact on flooding would likely be modest, for two main reasons:

- First, the flood-prone areas of southeastern Nepal and Bihar extend far beyond the Kosi basin. Figure 3 superimposes basin boundaries over the areas that were impacted by floods over the past decade. The image shows that most of the flooding in Nepal and Bihar lies outside the Kosi sub-basin. Floods in the basin are often caused by intense localized rainfall, high flows in small tributaries, embankment failures and obstructed drainage, rather than by peak flows overtopping embankments in the major tributaries where large storage reservoirs could be built to diminish flood peaks. The development of the Kosi High Dam or any other flood-control infrastructure upstream in the Kosi River would impact only a small part of the flood-affected areas downstream.

- Second, the level of the flood peak within the Kosi River is surprisingly unrelated to the extent of flooding in southeastern Nepal and Bihar. Development of the Kosi High Dam could bring down 


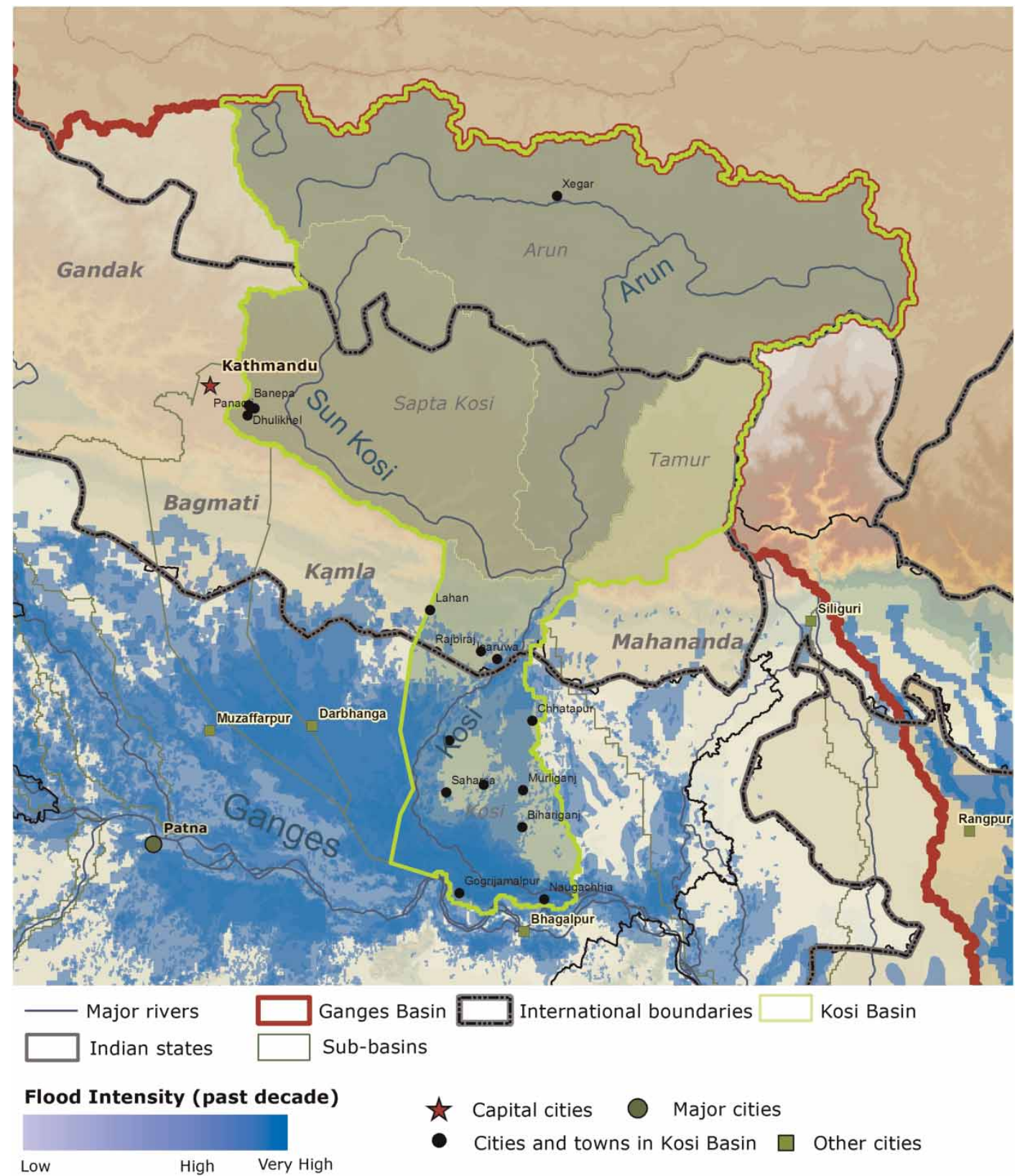

Fig. 3. Flooded areas and Kosi basin boundaries.

the flood peak in the Kosi River but the embankments on the Kosi River have never been overtopped by flood waters. Flooding in the Kosi has instead resulted from embankment failures, which suggests that embankment management should perhaps be prioritized over reservoir development as a flood control measure. 
While a moderate amount of flood flows could be stored in reservoirs on major Ganges tributaries, this adds little to flood relief because almost all of the major tributaries in the basin are fully embanked. Lowering flood peaks within these embanked rivers may provide some localized flood relief but it would do so only at the tributary level and not effectively address the range of factors that contribute to flooding along the main stem of the Ganges.

\section{Question 3. Can upstream water storage in Nepal augment low flows downstream?}

Himalayan reservoirs are expected to release water stored during the wet season for use in the dry season. It is widely believed that these releases could augment low flows for ecosystems, agriculture and other uses across the lower Gangetic basin, especially in the dry months preceding the monsoon (Kayastha, 2001; Bhaduri \& Barbier, 2003). Modelling results confirm this expectation.

Low-flow augmentation could indeed be significant if all the large dams proposed for Nepal were built, approximately doubling low flows in the months with the lowest flows. Storing even a minor portion of the flood flows until the dry season could significantly increase low flows, especially in a very dry year.

However, the economic value of low-flow augmentation is unclear. Even though the Ganges basin is home to some of the largest irrigated areas in the world - and about $90 \%$ of the water abstracted in the basin is used for irrigation - overall agricultural productivity is very low.

Lack of agricultural modernization - not lack of water - is the crucial constraint to agricultural productivity in many of the specific areas of the Ganges basin that could receive these additional low flows. Even if proposed dams were built (at high costs and likely over decades) agricultural modernization would be required to increase productivity. This modernization would be beneficial regardless of upstream dam construction.

Without better water management in irrigated areas, augmented low flows could have the paradoxical effect of reducing the productivity of some land in Bihar and eastern Uttar Pradesh that have high groundwater levels even in the dry season. These areas tend to recover slowly during the dry season as they drain and soil moisture evaporates. Augmenting low flows in such areas could disrupt this process of dry-season soil recovery, and actually cause harm by increasing waterlogging and reducing productivity.

In addition to potential agricultural gains, increased low flows could make important contributions in the Ganges delta areas. These increased low flows could better manage saline intrusion, sustain the Sundarbans ecosystem and maintain navigation services. These are important issues that require additional research to better understand their socio-economic and environmental implications throughout the Ganges system.

\section{Question 4. Are there good alternatives or complements to reservoir storage in the basin?}

Many believe that large infrastructure (dams) is the only option of adequate scale to meet the basin's water storage needs, given the region's growing populations and economies (Swain, 1993; Onta, 2001). The SBA finds that enhanced, sustainable use of the basin's vast groundwater aquifers could deliver additional water on a scale comparable to the full suite of large dams in the Nepal Himalaya.

Despite the severe overabstraction of groundwater seen elsewhere in South Asia, there are vast, untapped groundwater resources in the central and lower reaches of the Ganges basin. These additional groundwater resources, held in natural underground aquifers, can be used sustainably. 
As the Himalaya rose from the ocean, much of what today is the Ganges basin was formed by alluvial deposits from the rising and eroding mountains, resulting in an extensive aquifer that is several kilometres deep in some areas. It is a complex, multi-layered system interspersed with clay layers and perched aquifers with possibly an extensive deep aquifer as well, though this has not yet been well explored (see Figure 4).

Increased strategic and sustainable use of this groundwater, in conjunction with a well-managed surface water system, could provide water supply benefits on a scale comparable to the full suite of dams contemplated for construction by Nepal, and it could possibly do so more immediately, at national, state or local levels and at lower financial, social and environmental costs.

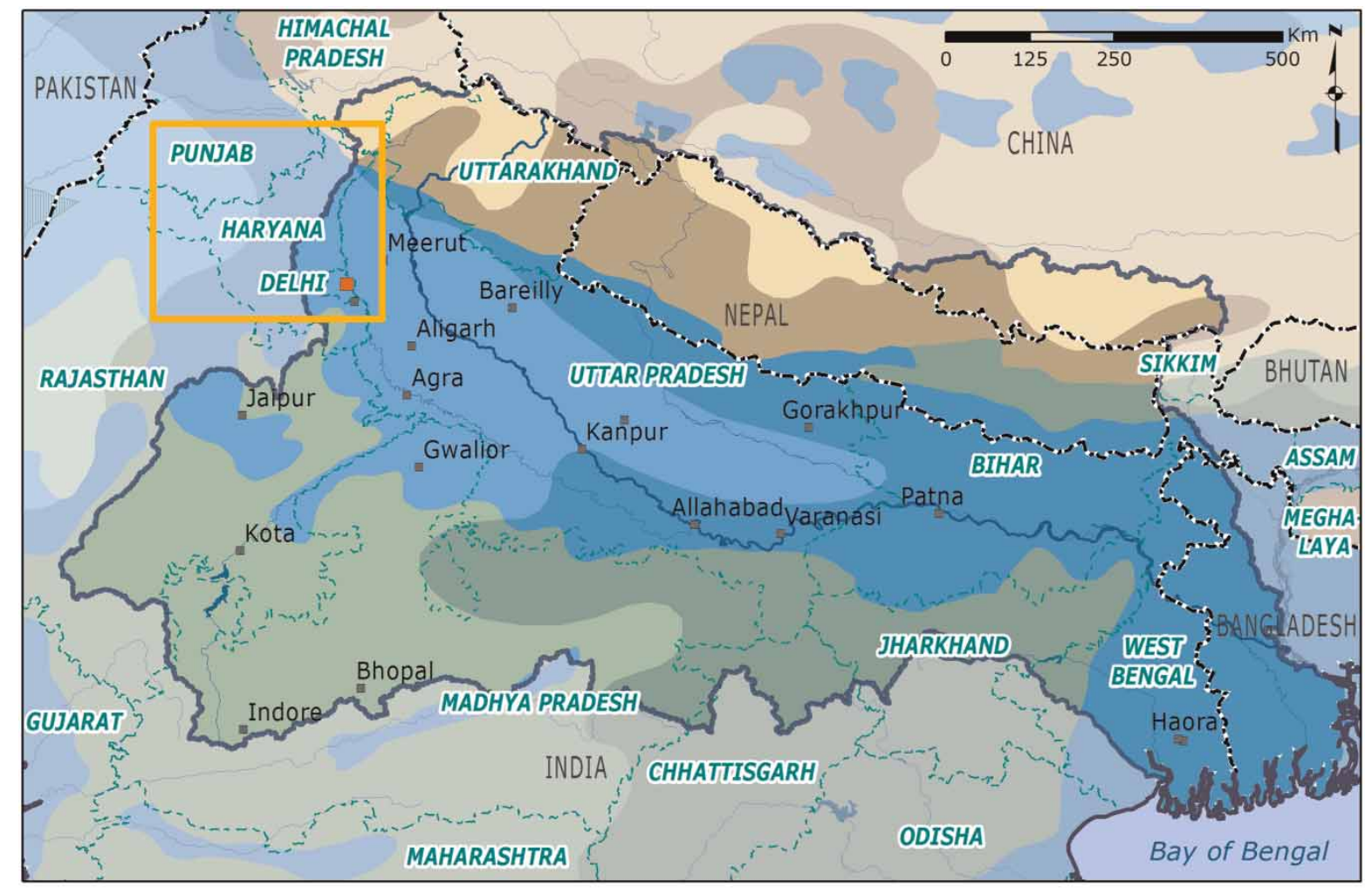

Groundwater recharge $(\mathrm{mm} / \mathrm{a})$

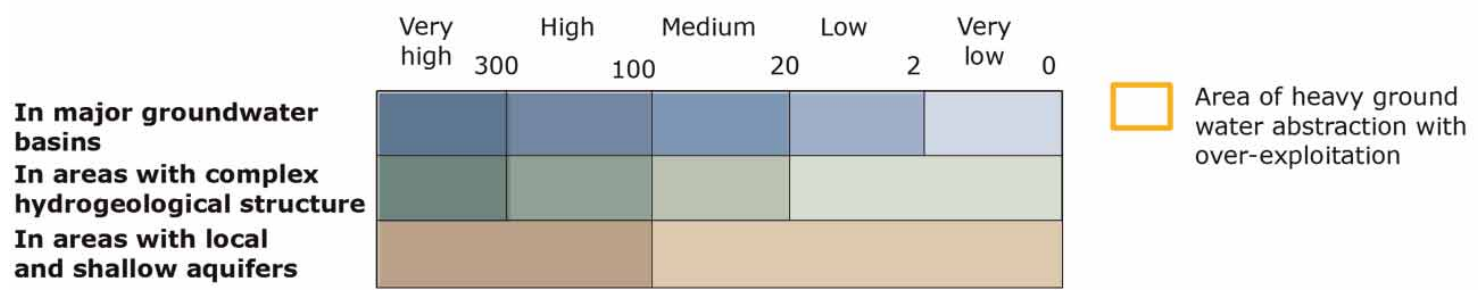

Fig. 4. Ganges basin groundwater potential. 
A conjunctive use strategy (integrated management of surface and groundwater) could be designed to help manage waterlogging and enhance the reliability of water supplies to tail-end users in surface irrigation schemes and/or downstream irrigators in the eastern basin. It would also require significant energy inputs, as energy is needed to access (pump) groundwater. Achieving all of this, however, would require significant reforms, particularly in the policy and energy-pricing environment, adequate institutional capacity and real changes in farmers' behaviour.

The storage available in the shallow alluvial aquifers of eastern Uttar Pradesh and Bihar, which could be utilized in the dry season and naturally recharged in the wet season, is 30-50 billion $\mathrm{m}^{3}$ (SMEC, 2009). This is comparable to the low-flow augmentation $\left(40-60\right.$ billion $\left.\mathrm{m}^{3}\right)$ that could be achieved with the construction of 23 large dams in the Nepal Himalaya. Moreover, the water from upstream dams would suffer evaporative and leakage losses as it travelled downstream, and the timing of water availability could not be targeted as precisely as the pumping of groundwater directly by a farmer onto his or her own fields.

Seasonal use of the groundwater aquifer for water storage deserves careful consideration as a storage option in the basin, with or without additional investment in upstream reservoir storage.

\section{Question 5. Is there substantial untapped hydropower potential in the Ganges basin?}

The Himalaya have long been seen as holding enormous hydropower potential, adequate to meet domestic energy needs in Nepal (where potential supplies far outstrip potential demand) and provide a significant surplus for trade in the region (Shibusawa, 1987; Ahmad, 2003; Bhaduri \& Barbier, 2003). The SBA confirms this potential.

In Nepal, more than 40,000 megawatts of economically feasible hydropower potential is believed to exist in the Himalayan headwaters of the Ganges. Less than $2 \%$ of that potential has been developed. The suite of dams examined in the Ganges SBA would have an installed capacity of about 25,000 megawatts, generating an estimated 65-70 terawatt hours of power annually. The net economic value of this potential hydropower is estimated at some US\$5 billion annually, quite significant relative to Nepal's 2011 gross domestic product (GDP) of US\$18.9 billion (in 2013 dollars).

Hydropower development on this scale would, however, require considerable capital investment and take many years, and sediments would need to be effectively managed. Nonetheless, hydropower is an important source of clean energy in a region that is enjoying high economic growth and hence has rapidly growing power demands.

\section{Question 6. What is the magnitude of potential economic benefits from a multi-purpose water infrastructure and what are the tradeoffs among different water uses?}

There is a general sense in the region that multi-purpose water infrastructure, such as storage-backed hydropower dams, will generate significant economic benefits (Onta, 2001). Yet there is no clear sense of the relative values that will be generated by hydropower, flood control and low-flow augmentation, nor of the tradeoffs among uses (and hence users). The Ganges SBA found that the overwhelming share of benefits (75-90\%) derive from hydropower and that tradeoffs between uses are rather small.

The Ganges SBA found that the gross economic benefits of hydropower from the 23 large dams examined under different scenarios of infrastructure development would be in the range of US\$3-8 billion per year (assuming that $25 \%$ of it could be sold as higher-value peaking power). Without taking into 
account project-specific environmental and social mitigation costs, the total net economic value of hydropower would likely be about US\$5 billion per year.

Economic benefits for downstream agriculture and ecosystems are particularly difficult to determine but they are likely to amount to less than 10-25\% of the gross economic benefits of the dams. The evidence suggests that the current marginal (net) economic value of increased surface water for irrigation is quite low in India and Nepal, at around US\$0.01 per $\mathrm{m}^{3}$. If this is true, and no clear economic value can be attached to ecosystems services, then over $90 \%$ of total economic benefits will come from hydropower. If the value of additional irrigation water were US\$0.05 per $\mathrm{m}^{3}$ (a level of agricultural productivity that should be achievable but almost certainly overstates current returns) and the value of ecosystem services were US\$0.01 per $\mathrm{m}^{3}$, the distribution of incremental economic benefits from development of all of the proposed large dams in the Nepal Himalaya would be roughly $74 \%$ from hydropower, $18 \%$ from irrigation and $8 \%$ from ecosystem services (see Figure 5).

In the future, if agricultural productivity were enhanced, those benefits could rise dramatically. If the ecosystem benefits were better understood and quantified, they could be much larger than we have assumed for illustrative purposes in these calculations. Even so, the absolute value of economic returns to hydropower would remain fairly stable because the tradeoffs between upstream hydropower uses, on the one hand, and downstream agriculture and ecosystem uses on the other, are smaller than previously assumed.

For the most part, the economic tradeoffs among hydropower, irrigation, flood control and ecological objectives are small. This is because there is little difference in the way upstream dams would be operated to maximize hydropower generation, on the one hand, and downstream water supply on the other. The objective for both is to store peak flows to achieve steadier dry-season releases; the same water that generates hydropower would augment low flows in the dry season. The ability to control downstream flooding is limited regardless of the design and operation of dams, so there is little tradeoff anticipated between hydropower and flood control.

There is a tradeoff between using water for irrigation in the Ganges plains versus low-flow augmentation to sustain ecosystem services in the delta, but there is currently insufficient evidence to determine whether this tradeoff is economically significant. The evidence suggests that the marginal economic benefit associated with surface water irrigation in the plains is currently quite low and the economic value of increased low flows for ecosystem services is uncertain.

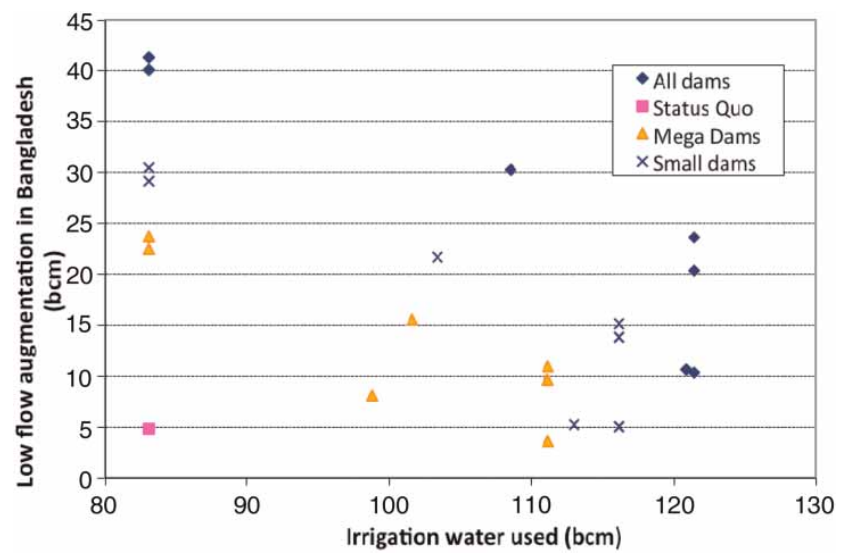

Fig. 5. Distribution of economic benefits from all proposed large dams. N.B. bcm = billion cubic meters. 


\section{Question 7. What are the cost- and benefit-sharing dynamics of upstream water storage development in Nepal?}

It is generally perceived that downstream countries will benefit greatly from upstream development and therefore should share the costs of that development (Khan, 1996; Mirza, 2005). Some believe that the majority of benefits from upstream water storage will not accrue from hydropower development upstream, but rather from flood control and irrigation benefits downstream. A common understanding of the distribution of benefits is essential to negotiating equitable benefit-sharing arrangements.

If upstream multi-purpose dams were built today, with current low agricultural productivity and little flood benefit, the overwhelming share of economic benefits (over 75-90\%) would be derived from hydropower. In the future, if agricultural productivity rises dramatically, the distribution of benefits could change.

Tradeoffs among different water uses are modest. Infrastructure would be designed and operated much the same way whether the goal was to maximize hydropower or to maximize flood and irrigation benefits downstream. The small amount of storage relative to the flow of the Ganges or its tributaries would mean that reservoir-filling policies are a manageable issue. And smaller storage areas mean less inundated land and less resettlement of people. Negotiations over the design and operation of multi-purpose infrastructure with transboundary impacts should therefore be more than previously thought, and power revenues will lie at the heart of any benefit-sharing negotiations. Delays in negotiations could result in lost power revenues that could actually be greater than the benefits of upstream storage for flood control and downstream ecosystems.

Flood benefits are minor and confined to tributaries. Upstream storage will have negligible basin-wide flood impact. Benefit sharing with regard to flood protection could, therefore, be appropriately negotiated at the tributary scale (i.e. between two countries), rather than basin wide. Conversely, benefit sharing with regard to enhancing low flows for irrigation and ecosystems remains an appropriate issue for basin-wide discussions.

The principal unknowns in this equation are the ecosystem and navigation values of enhanced low flows in the delta, which could be significant. The Ganges SBA's findings suggest, however, that the benefit-sharing calculus is simpler than previously assumed because downstream flood control and agricultural benefits are smaller than anticipated - at least in the near to medium term.

\section{Question 8. Is large infrastructure in Nepal the best strategy for protecting downstream communities from floods?}

Infrastructure is often seen as the most effective and reliable way to protect communities from endemic flooding in the Ganges plains (Swain, 1993; Huda \& Shamsul, 2001; Salman \& Uprety, 2002). The findings of the Ganges SBA, however, show that a strategy exclusively focused on large upstream infrastructure cannot effectively protect communities lower in the basin.

There is no simple solution to the problem of flooding on the Ganges plains. In some areas of the world, a focus on large infrastructure (dams and embankments) has been fairly effective. However, in the highly variable Ganges system, with its thousands of silt-laden tributaries and limited storage, these solutions will not be very effective.

Droughts and floods take a significant toll on lives and livelihoods in the basin, and physical exposure to water-related risks is closely linked with social vulnerabilities in the region. The least-advantaged 
populations tend to live in areas with higher physical risks, while those with economic options tend to move away from the most physically insecure spaces. To control flooding, many major tributaries are extensively embanked. However, these embankments often fail, resulting in unanticipated and often catastrophic flooding.

To protect vulnerable communities in the Ganges basin, a shift in focus is needed from 'flood control' to 'flood management', a combination of structural and nonstructural interventions marked by a greater emphasis on regional forecasting and warning systems, embankment asset management, drainage and, importantly, more localized 'soft' responses including disaster preparedness, land-use zoning, safe havens, flood insurance and communications campaigns. Indeed, in recent years, this shift has been the subject of a great deal of thoughtful advocacy. Flood protection for basin communities and the livelihoods of their people requires a broad, balanced combination of 'hard' and 'soft', as well as local and transboundary responses (Dixit, 2009).

Embankments remain the chief 'hard' response to floods in the Ganges basin. Their long-term impacts have been mixed and mounting criticism is challenging the paradigm of using structural investments to control flooding. Some critics point to the fact that embankment systems have altered the hydrological characteristics of the basin because high silt loads (typically spread on the plains areas during flooding) are now deposited within the embankments, raising river beds, reducing the capacity of the embanked channel to carry floods safely downstream and increasing the risk of embankment failure (Figure 6).

Embankment failures can be catastrophic. Embankment breaches or failures - like the devastating Kosi Embankment breach of 2008 - bring on sudden severe flooding that catches communities offguard. At the same time, the presence of embankments can foster a false sense of security that manifests in a lack of preparedness, reduces social awareness of risk and encourages behaviours such as settlements in historic flood plains, thereby actually increasing vulnerability.

Still, once built, embankments must be managed effectively: embankment monitoring and maintenance are an imperative for protecting communities in the Ganges basin. If modern embankment management systems are introduced, they can help assess needs for maintenance, optimize resource allocation, and save lives and livelihoods.

In the Ganges basin, flood waters must be managed both within the embankments and outside. Embankments disrupt drainage. River beds contained within embankments will rise as a result of the constant supply of sediment from the high Himalayas. As a consequence, embankments must be constantly raised to ensure they do not overtop. As embankments are raised, they interrupt the normal flow of countless small tributaries that can no longer make their way into the main river system and drain off the land. In some reaches, drainage structures were designed into embankments but many of these are now in disrepair or buried under decades of silt deposits. A modern embankment management system must prevent floods extending outwards from the river channel and also ensure drainage of the broad flood plain.

Beyond embankment management, much can be done through 'soft' approaches to forecast flood events and prepare communities to deal with them. Today's revolutionary technological advances in satellites, radar systems and real-time hydrometeorological systems, forecasting techniques, decision support systems and last-mile communication hold much promise for the basin.

Regional flood information systems and institutions could be immediately beneficial. Building on national systems and capacities, regional cooperation in the development of basin-wide water, weather and climate information management, forecasting capacity and disaster warning systems could provide national institutions with significantly enhanced forecasts for action. 

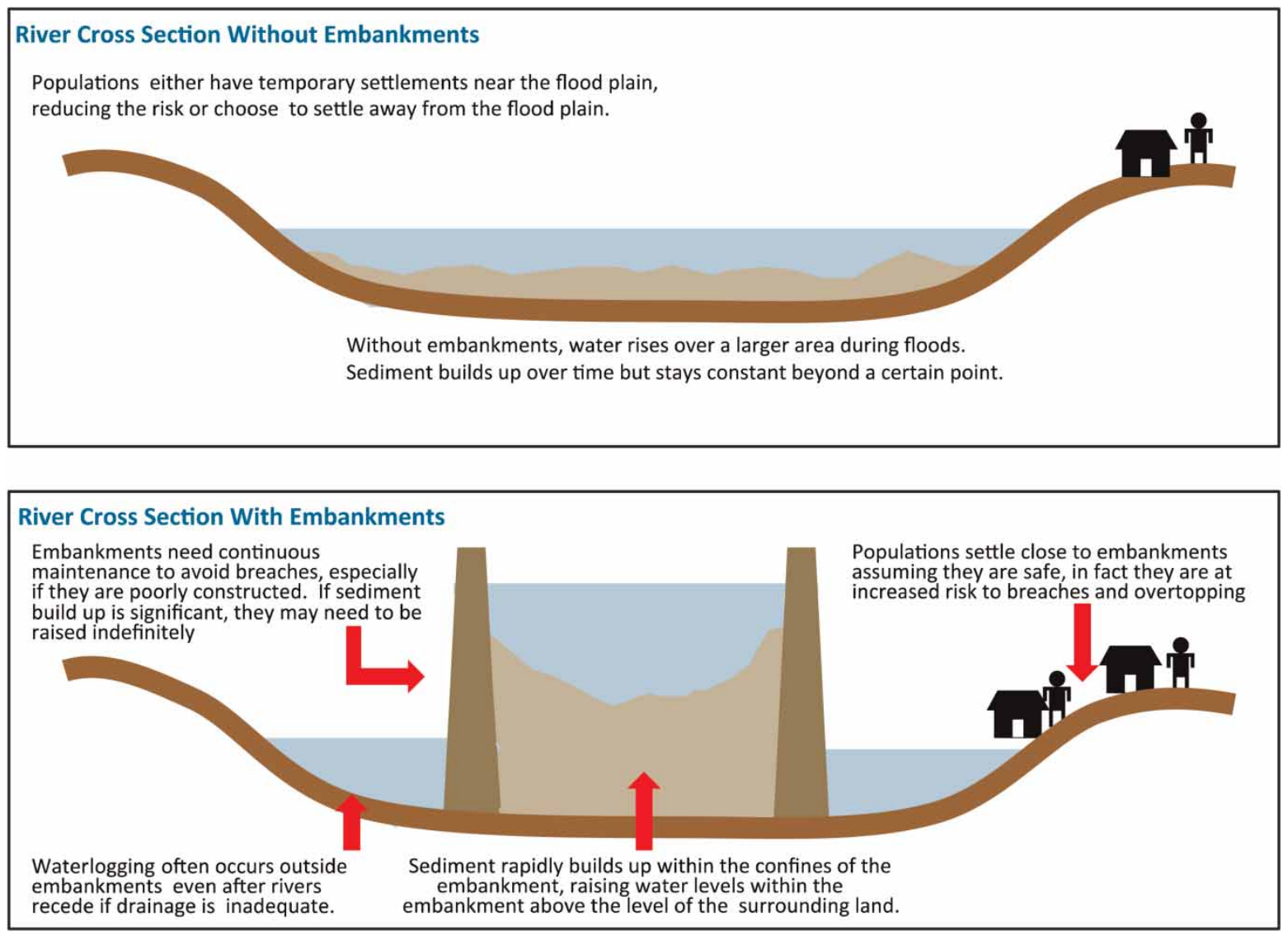

Fig. 6. Schematic of embankments in sediment-laden rivers.

Effective protection of communities also requires particular attention to gender. Studies in Bangladesh have shown that women and children are 14 times more likely to die in the event of a natural disaster than men (Neumayer \& Plumper, 2007). Gender concerns also endure after natural disasters. In focus group discussions undertaken for the Ganges SBA, women claimed that in the aftermath of a disaster, when there was limited food available to their families, they were generally the last to eat. Special attention must be paid to women's needs and ideas in the design of appropriate flood management strategies.

\section{Question 9. Is it possible to control sediment in the Ganges?}

Many believe that in the Ganges, like elsewhere in the world, a combination of watershed management to control erosion and upstream storage structures might control sedimentation in the river (Mirza, 2002; Dixit, 2009). But the Ganges is different.

The Ganges is one of the three most sediment-laden rivers in the world. Most of the sediment comes from erosion in the high Himalaya. The altitude and terrain of the high Himalaya sediment source regions, as well 
as the nature of the soils and the ongoing tectonic processes, make it impossible to undertake the scale of watershed management interventions necessary to have any measurable impact on basin sediment loads.

The standard watershed management practice of reducing erosion by extending and maintaining forest cover at the source of a watershed is not effective at high altitudes above the tree line. Although Nepal has an impressive history of community forestry management, with good results in local erosion management and livelihood benefits, these activities are predominantly undertaken in the Siwaliks or Churia Hills at elevations of just 600-1,200 meters above sea level, far below the main sediment source regions at 2,000-8,000 meters.

The extremely high volume of sediment also makes it difficult and costly to manage using reservoir capture and storage. The volume of sediment is so large that dams could not, and should not, be designed to capture and store it. The reservoirs behind these large, expensive structures would quickly fill with sediment and, thereafter, produce very few benefits and potentially pose a real safety risk. In fact, the dams would need to be operated to try and reduce sediment build-up. If new dams are to be built in the Nepal Himalaya, managing sediment within the reservoir will be a central design challenge. Any infrastructure developed in the Ganges system would need sophisticated systems for flushing sediment downstream.

Sediment, like floods, is a challenge that must be managed in the Ganges basin; it cannot be fully controlled. Choices that are made today potentially foreclose alternative options in the future. Continuing to raise embankments will result in the deposit of sediments inside the embankments and lift the level of the river bed. Such a policy is increasingly hard to reverse.

\section{Question 10. What will climate change mean for the basin?}

Many fear that the Himalayan glaciers will melt and change the Ganges River from a perennial to a seasonally flowing river, and that changing temperatures and precipitation patterns will create crippling water stress as well as more severe and more frequent droughts and floods (Milliman \& Ren, 1995; Onta, 2001; Schubert et al., 2007). The SBA found that climate change uncertainties in South Asia and the Ganges basin in particular are extreme but that the range of mean basin runoff predictions is roughly comparable to the basin's highly variable climate today.

The Ganges SBA estimated temperature, rainfall and runoff for the Ganges basin using 16 Intergovernmental Panel on Climate Change-recognized Global Circulation Models. Although there appears to be a clear trend toward rising temperatures, predictions regarding rainfall and runoff vary widely and are inconclusive as to whether water availability will increase or decrease. The range of model results underscores their uncertainty, and their predictions can mask extremes, but these results do suggest that the scale and focus of today's climate challenges - unpredictable and intense rainfall, alternating extremes of flood and drought - will continue to be the key climate challenges in the coming decades. A focus on managing current hydrological variability (whether or not it is attributable to climate change) is, therefore, a good place to start addressing the future climate change challenges of the Ganges.

With regard to the glaciers, the Ganges SBA found that while the rate of glacier melt is likely to increase somewhat, glacier melt contributes only about $2 \%$ of basin-wide flow. In addition, melting occurs mostly during the high-flow season in the Ganges basin. In contrast to Europe and North America, or even in the western Himalaya, where glacier melt contributes substantially to low summer flows, 
the Himalayan glaciers in the Ganges basin melt during the monsoon season when temperatures are highest but rainfall is also heaviest. Thus, while changes in glacier melt will be an existential challenge for some melt-dependent mountain communities, it is not a major driver of basin-wide hydrology in the Ganges. The recession of glacier 'tongues' is not a reflection of the larger glacier mass that responds slowly to topography and climate.

The snow system, on the other hand, responds much more quickly to changes in temperature and precipitation. The expected temperature increase in all seasons will result in less precipitation accumulating as snow and in faster melting. The changes expected in the distribution, timing and intensity of precipitation would further complicate the process of snow accumulation and melt. The snow acts as a natural 'reservoir' in the Himalaya, storing monsoonal precipitation and augmenting low flows; the reduction of this function could impact seasonal runoff, especially during critically low flows.

Even the most extreme climate scenarios do not change the basic findings of the Ganges SBA. In fact, greater climate extremes, variability and uncertainty only strengthen the logic of the Ganges SBA's basic recommendations. While effectiveness of large-scale infrastructure for flood control, and the reliability of existing large-scale diversions of surface water for irrigation, could prove susceptible to climate change, the recommendations of the Ganges SBA are likely to become more pertinent under greater climate extremes. Enhanced forecasting and warning systems, in concert with a suite of tailored, localized responses, are urgently needed to cope with the variability currently seen in the basin and will be all the more vital as the climate changes. Similarly, the need for enhanced conjunctive use of surface water and groundwater only becomes more compelling as temperatures and hence evaporation rates, increase.

In fact, concern about the additional uncertainty that climate change could bring to the Ganges system could be a unifying factor in bringing basin riparians together for greater cooperation.

\section{Concluding remarks: the way forward}

There are daunting challenges in the Ganges River basin but there are also many opportunities for cooperation and productive management of rivers and water resources.

There is broad international consensus that basins should be managed holistically and a range of river basin committees, commissions and organizations around the world seek to institutionalize these good practices. The Ganges could benefit from the creation of an inclusive river commission that could develop a shared knowledge base and operational model of the basin, establish norms and protocols for transparency and information sharing, and identify and pursue opportunities for cooperative development projects.

Recognizing that the basin states may choose not to establish a river basin organization in the near term, the Ganges SBA identifies opportunities to achieve some of the key functional benefits without the need for a full basin organization.

Flood management would be an excellent initial focus for enhanced regional cooperation within the current institutional environment. Large dams built to hold back floodwaters high in the Himalaya have long been seen as the preferred strategy for managing the region's devastating floods. But as an exclusive strategy, this is untenable. The physical storage volume available in the mountains is simply too small to have a meaningful impact on basin-wide floods, although reservoirs may provide some amelioration within tributaries. The SBA's findings argue for redoubling efforts in flood management, and in particular investments in regional information, forecast and warning systems and/or institutions, 
coupled with a range of hard and soft, national and local level investments. In addition to helping disaster risk management professionals to safeguard lives and assets, these systems could also help provide the scientific data needed by planners to sustain and develop the basin, by farmers to enhance productivity and food security, and by climate researchers to understand, predict and adapt to the changing - but also immediately challenging - climate in the Ganges basin.

Immediate opportunities are also apparent at the bilateral and/or regional level for hydropower development and trade. There is significant untapped potential in the basin and a steadily growing demand for clean energy. Moreover the benefit-sharing calculus of hydropower development appears simpler than commonly believed, for several reasons: (i) the tradeoffs among different water uses (and hence users) are modest; (ii) the current economic value of downstream irrigation is surprisingly small compared with hydropower benefits; and (iii) flood benefits are minor and largely confined to tributaries. This should simplify negotiations.

Opportunities to enhance low-season water availability were also identified. Low flows can be significantly augmented (potentially doubled in the dry months) as a co-benefit of developing multi-purpose storage reservoirs upstream. But the development of upstream storage reservoirs is a costly undertaking, and the Ganges SBA suggests that storage investments would not be economically justifiable solely - or even significantly - on the grounds of their immediate contribution to enhancing agricultural productivity in the basin. The productivity of large areas of waterlogged land could potentially be diminished if more water were applied during the dry season, which is a time that usually allows for recovery.

Upstream storage alone will not modernize agriculture in the basin. A range of interventions is needed (and some are underway) to enhance agricultural productivity and support the livelihoods of poor farmers. These interventions are likely to be beneficial regardless of the development of upstream storage.

A promising and potentially more timely and cost effective national-level alternative to upstream water storage reservoirs is the use of underground aquifers. There is great potential to augment low-season flows by increasing groundwater utilization, within an appropriate energy-pricing and policy environment and in conjunction with a well-managed surface water system. In eastern Uttar Pradesh, enhanced groundwater use could produce additional storage (and hence augment dry-season water availability) on a scale comparable with the Himalayan dams, but likely much more rapidly, and at lower cost. Enhanced groundwater use would also be more scalable than water storage in the Himalaya. If upstream multi-purpose dams are found to be economically, socially and environmentally justified by the bundle of benefits they can produce, additional dry-season water could prove to be a co-benefit perhaps to complement more immediate interventions in conjunctive use.

Enhanced low-season flows may also hold important potential to sustain ecosystem services, particularly in the fragile Sundarbans (mangrove forests) of the Ganges delta. The ecosystem values of increased low flows downstream (e.g. in distributary rivers such as the Gorai, which was once the mouth of the Ganges) remain unsubstantiated, though they might be high. Less expensive interventions such as dredging through the sandbar that currently impedes the flow of Ganges water into the Gorai in the nonflood season could improve low flows into that system even without upstream augmentation. A final important unknown is the economic value of augmented low flows in combating saline intrusion in the delta, and the importance of the Ganges freshwater plume for the dynamics of currents and storm patterns in the Bay of Bengal. More study of the morphology and ecosystems values in the Ganges delta is urgently needed.

Sediment management is a perennial challenge in the basin. The extremely high volume of sediment that erodes off the high Himalaya cannot be effectively controlled through watershed management or captured in reservoirs. A sediment strategy is needed. Ideally such a strategy would integrate sediment, 
flood and land-use management, and would explore tools ranging from modern embankment and drainage management, to planned inundation areas, land zoning and insurance schemes. The choices made today around sediment and flood management will be fundamental basin development choices that 'lock in' options for generations to come. In the absence of a strategy, basin managers can only react in an ad hoc manner to imminent threats and periodic catastrophes.

Finally, significant climate change and other uncertainties remain in the basin. Current data and models give little clear evidence of what the future holds. But perhaps this uncertainty itself could be a reason for enhanced cooperation. It appears that mean hydrological variability in the future will be similar to the pronounced variability seen in the basin today but extremes may well be greater. Greater climate extremes, however, would only strengthen the justification for the main recommendations. Investing in cooperative information management, forecast and modelling systems at the regional level, along with a range of tailored interventions at the national and local levels, would enhance productivity and resilience in the Ganges basin today, as well as the capacity to manage climate change in the future.

\section{References}

Ahmad, Q. \& Ahmed, A. (2005). Regional cooperation on water and environment in the Ganges basin: Bangladesh perspectives. In: The Ganges Water Diversion: Environmental Effects and Implications. Kluwer, Dordrecht, The Netherlands, pp. $305-325$.

Ahmad, Q. K. (2003). Regional cooperation in flood management in the Ganges-Brahmaputra-Meghna region: Bangladesh perspective. Natural Hazards 28(1), 191-198.

Bhaduri, A. \& Barbier, E. B. (2003). Water Transfer and International River Basin Cooperative Management: The Case of the Ganges. Department of Economics, University of Wyoming, Laramie, WY. http://www.uwyo.edu/barbier/projects/water\% 20 transfer $\% 20$ and $\% 20$ international $\% 20$ river $\% 20$ basin $\% 20$ cooperative $\% 20$ management $\% 20-\% 20$ the $\% 20$ case $\% 20$ of $\% 20$ the $\% 20$ ganges.pdf.

Dixit, A. (2009). Kosi Embankment breach in Nepal: need for a paradigm shift in responding to floods. Economic and Political Weekly 7, 70-78.

Huda, A. \& Shamsul, T. M. (2001). Constraints and opportunities for cooperation towards development of water resources in the Ganges basin. In: Sustainable Development of the Ganges-Brahmaputra-Meghna Basins. UNU Press, pp. 46-57.

Kayastha, R. L. (2001). Water resources development of Nepal: a regional perspective. In: Sustainable Development of the Ganges-Brahmaputra-Meghna Basins. UNU Press, pp. 122-144.

Khan, T. A. (1996). Management and sharing of the Ganges. National Resources Journal 36, 455.

Milliman, J. D. \& Ren, M. E. (1995). River flux to the sea: impact of human intervention on river systems and adjacent coastal areas. In: Climate Change: Impact on Coastal Habitation. CRC Press, pp. 57-83.

Mirza, M. Monirul Qader (1998). Diversion of the Ganges water at Farakka and its effects on salinity in Bangladesh. Environmental Management 22(5), 711-722.

Mirza, M. Monirul Qader (2002). The Ganges water-sharing treaty: risk analysis of the negotiated discharge. International Journal of Water 2(1), 57-74.

Mirza, M. Monirul Qader (2005). The Ganges water diversion: environmental effects and implications-an introduction. In: The Ganges Water Diversion: Environmental Effects and Implications. Kluwer, Dordrecht, The Netherlands, pp. 1-12.

Neumayer, E. \& Plumper, T. (2007). The gendered nature of natural disasters: the impact of catastrophic events on the gender gap in life expectancy, 1981-2002. Annals of the Association of American Geographers 97(3), 551-566.

Onta, I. R. (2001). Harnessing the Himalayan waters of Nepal: a case for partnership for the Ganges basin. In: Sustainable Development of the Ganges-Brahmaputra-Meghna Basins. UNU Press, pp. 100-121.

Rahaman, M. M. (2005). Integrated Water Resources Management in the Ganges Basin: Constraints and Opportunities. Department of Civil and Environmental Engineering, Laboratory of Water Resources, Helsinki. http://users.tkk.fi/ mizanur/Rahaman2005.pdf. 
Rahaman, M. M. (2009). Integrated Ganges basin management: conflict and hope for regional development. Water Policy 11 (2), 168-190.

Salman, S. M. A. \& Uprety, K. (2002). Conflict and Cooperation on South Asia's International Rivers: a Legal Perspective. World Bank Publications, Washington, DC.

Schubert, R., Schellnhuber, H. J., Buchmann, N., Epiney, A., Griesshammer, R., Kulessa, M., Messner, D., Rahmstorf, S. \& Schmidt, J. (2007). Climate Change as a Security Risk. WBGU Flagship Report. Earthscan, London.

Shibusawa, A. H. (1987). Co-operation in water resources development in the Ganges-Brahmaputra basins. Mountain Research and Development 7(3), 319-322.

SMEC: Snow Mountain Engineering Corporation International Pty Ltd (2009). Preparation of Ghanga Gomti Basin Plans \& Development of Decision Support Systems. Final Report prepared for the State Water Resources Agency, Uttar Pradesh.

Swain, A. (1993). Conflicts over water: The Ganges water dispute. Security Dialogue 24(4), 429-439. 